\title{
Total Collision Cross Sections for the Interaction of Molecular Beams of Cesium Chloride with Gases. Influence of the Dipole-Dipole Force upon the Scattering
}

\author{
Hugo Schumacher, Richard B. Bernstein, and Erhard W. Rothe* \\ Department of Chemistry, The University of Michigan, Ann Arbor, Michigan
}

(Received January 22, 1960)

\begin{abstract}
Total cross sections $(Q)$ for the interaction of beams of $\mathrm{CsCl}$ with a number of molecules were measured using an apparatus of ca $4^{\prime}$ angular resolution in which the temperature of the scattering gas could be varied from $200^{\circ}-735^{\circ} \mathrm{K}$. The temperature dependence of $Q$ was studied for $\mathrm{Ar}, \mathrm{CH}_{4}, \mathrm{CH}_{2} \mathrm{~F}_{2}, \mathrm{CHF}_{3}, \mathrm{CF}_{4}, \mathrm{NO}, \mathrm{H}_{2} \mathrm{~S}$, $\mathrm{NH}_{3}$, and for cis- and trans-CHCl=$=\mathrm{CHCl}$. Relative values of $Q$ at $300^{\circ} \mathrm{K}$ were measured for eight additional gases.

The data were correlated using the Massey-Mohr theory, assuming an intermolecular potential $V(r)=$ $-C / r^{6}$, so that $Q=b\left(C / v_{r}\right)^{2 / 5}$, where $v_{r}$ is the relative velocity and $b$ a known constant; the potential constant $C$ was estimated from formulas for the dispersion, dipole-induced dipole, and dipole-dipole forces.

For the nonpolar gases the observed small temperature dependence of $Q$ agrees within experimental error $( \pm 3 \%)$ with that expected from the temperature dependence of $v_{r}$. The theoretical values of $Q$ differ by a nearly constant factor from the experimental results; thus relative cross sections $\left(Q^{*}\right)$ are predicted with fair accuracy.

For the polar gases the Q's are large, decreasing significantly with increasing temperature. Because of the large dipole-dipole interaction, the approximate theoretical treatment (based on the limiting temperature-dependent dipole-dipole contribution to $C$ ) accounts only semiquantitatively for the observations.
\end{abstract}

\section{INTRODUCTION}

$\mathbf{I}^{\mathrm{s}}$ $\mathrm{N}$ a previous paper ${ }^{1}$ total collision cross sections $(Q)$ for the interaction of atomic beams of $K$ and $C s$ with a number of molecules (polar and nonpolar) were reported. The results were correlated with the MasseyMohr theory ${ }^{2}$ for an attractive intermolecular potential $V(r)=-C / r^{6}$.

The present paper describes experiments on the scattering of beams of the dipolar molecule $\mathrm{CsCl}$. Studies with dipolar beam molecules are of interest because of the possibility of observing directly the influence of the dipole-dipole forces upon the scattering.

An approximate theoretical equation has been presented ${ }^{1}$ for the estimation of elastic scattering cross sections :for dipolar molecules. The assumptions in its development are such as to limit its applicability to cases where the interaction energy is small relative to $k T$, corresponding to low dipole moments and/or high temperatures. It will be seen that although the experimental results may be accounted for in a semiquantitative way by the limiting theory, considerable further theoretical development is needed before precise a priori calculations of cross sections can be made.

\section{EXPERIMENTAL}

The apparatus was that described by Rothe and Bernstein $^{1}$ (hereafter referred to as I) with the following modifications: The oven was supplied with additional

\footnotetext{
* Present address: Physics Section, Convair San Diego, Division of General Dynamics Corporation, San Diego, California.

1 E. W. Rothe and R. B. Bernstein, J. Chem. Phys. 31, 1619 (1959). Errata are as follows: The exponent in Eq. (2) should read -17 . The first bracket in $\mathrm{Eq}$. (e) of Appendix II is to be deleted. A more correct estimate of the angular resolution is $2^{\prime}$ of arc (see footnote 3 of the present paper).

2 H. S. W. Massey and C. B. O. Mohr, Proc. Roy. Soc. (London) A144, 188 (1934)
}

heaters and surrounded by a water-cooled radiation shield. The oven slit was set at $0.005 \mathrm{~cm}$. The scattering chamber (SC) was constructed of copper, with a Kovarto-Pyrex seal leading to the external gas inlet system. It was attached to a Monel heater plate containing internal heating coils. This plate was itself in contact with a copper cooling plate through which liquid nitrogen could be passed. The SC was thermally insulated from its support by means of Vycor plates and rings. Three thermocouples located in suitable wells in the SC indicated that temperature gradients were negligible. Steady temperatures ranging from $-130^{\circ}$ to $465^{\circ} \mathrm{C}$ could readily be obtained; however, for other reasons the low-temperature limit of the experiments was set at $200^{\circ} \mathrm{K}$.

The collimating slit on the SC was set at $0.005 \mathrm{~cm}$. The calculated half-width of the unscattered beam at the detector $(0.0025 \mathrm{~cm}$ diam) was $0.015 \mathrm{~cm}$. The observed value varied somewhat with the temperature of the SC, but was in the range $0.02-0.03 \mathrm{~cm}$. The resolution $^{3}$ of the apparatus is taken to be $4^{\prime}$ of arc (compared to $2^{\prime}$ with the arrangement used in $\mathbf{I}$ ).

The Knudsen-gauge (KG) sensitivity was improved to a value of $2.0 \times 10^{-6} \mathrm{~mm} \mathrm{Hg} / \mathrm{mm}$ scale deflection by increasing the heater temperature and the optical path. The working range of pressures in the SC was from $1 \times 10^{-6}$ to $5 \times 10^{-5} \mathrm{~mm} \mathrm{Hg}$. Since the $\mathrm{SC}$ was at a

${ }^{3}$ P. Kusch (private communication, January 18, 1960) has developed an equation for calculating the efficiency of detection of scattering in terms of apparatus parameters, e.g., beam width and detector width. He suggests a reasonable definition of resolution as the minimum scattering angle for which the efficiency of detection of scattering is $50 \%$. This criterion has been adopted here. Note added in proof. Application of this analysis to the experimental arrangements of two other previous workers (footnote references 2 and 10 of $I$ ) showed their resolution (at the $50 \%$ level) to be appreciably worse than their stated "resolution." 
different temperature than the $\mathrm{KG}$, the pressure readings required correction for the thermal transpiration effect, $P_{\mathrm{SC}}=P_{\mathrm{KG}}\left(T_{\mathrm{SC}} / T_{\mathrm{KG}}\right)^{\frac{1}{2}}$. The ideal square root of $T$ factor was used in view of calculations based on Liang' $\mathrm{s}^{4}$ empirical formula for thermal transpiration, using the present experimental parameters $\left(P<5 \times 10^{-6}\right.$ $\mathrm{mm}$, tubing diam $9 \mathrm{~mm}$ i.d., $T_{\mathrm{sc}} 200-735^{\circ} \mathrm{K}$, and $T_{\mathrm{KG}}=$ $300^{\circ} \mathrm{K}$ ). The calculated factors agreed within $1 \%$ with the ideal $T^{\frac{1}{2}}$ factor used.

Larger liquid-nitrogen traps made it possible to maintain pressures $<3 \times 10^{-7} \mathrm{~mm} \mathrm{Hg}$ in the oven chamber and $<2 \times 10^{-7} \mathrm{~mm} \mathrm{Hg}$ in the detector chamber with both the oven and SC at high temperatures.

The operating procedure was similar to that described in I. Before each series of experiments with a new scattering gas, however, the SC was heated and thoroughly degassed. For each individual cross-section determination the beam intensity was measured for 20 or more values of the scattering gas pressure corresponding to $0-50 \%$ attenuation of the beam. Plots of $\log \left(I / I_{0}\right)$. vs $P_{\mathrm{SC}}$ were accurately linear in this range $\left(I / I_{0}>0.5\right)$.

Argon was used as a standard "reference" gas; for comparison purposes the $Q$ for argon was determined at least once during any series of measurements with another gas. In I, relative cross sections were reported (using argon as the reference). In the present work, whenever the argon cross section differed significantly from the "standard" argon curve (Fig. 2) all $Q$ 's of that series were adjusted accordingly (by amounts ranging from 0 to $14 \%$ ). All data as reported are thus mutually consistent with the "standard" curve for argon.

\section{MATERIALS}

All scattering gases were purified (mostly by distillation) and were characterized before use. They are believed to contain less than $1 \%$ impurity. We used cp cesium chloride (Fairmount Chemical Company), stated to contain $<0.5 \%$ impurity (most of which is $\mathrm{KCl}$ ), for the beam. Based on the results of $\mathrm{Kusch}^{5}$ it is unlikely that the abundance of dimeric or polymeric molecules in the beam is greater than $1-2 \%$.

\section{RESULTS}

Figure 1 shows a typical plot of primary data. The calculation of the cross section from the slopes of such graphs is outlined in $\mathbf{I}$.

The absolute cross sections for $\mathrm{CsCl}$-argon are subject to uncertainty because of numerous sources of possible systematic errors. ${ }^{1}$ For the earlier measurements ${ }^{6}$ (Set $\mathrm{A}$, beam temperature $876^{\circ} \mathrm{K}$ ) the average value of $Q$ for argon at $300^{\circ} \mathrm{K}$ was $395 \mathrm{~A}^{2}$ with a maximum value of $450 \mathrm{~A}^{2}$. However, for the subsequent, more

\footnotetext{
${ }^{4}$ S. C. Liang, J. Phys. Chem. 57, 910 (1953).

5 P. Kusch, J. Chem. Phys. 25, 860 (1956).

${ }^{6}$ E. W. Rothe, Ph.D. thesis, University of Michigan, 1959. Available from University Microfilms, Inc., Ann Arbor, Michigan.
}

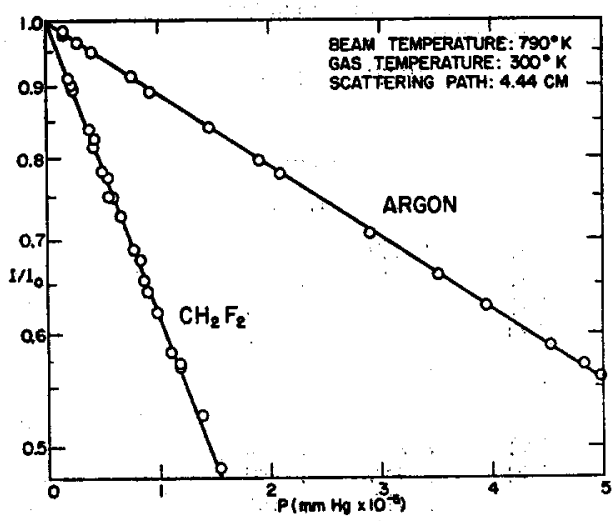

FIG. 1. Typical plot of primary data for $\mathrm{CsCl}$ scattering.

reliable determinations (Set B, beam temperature ca $790^{\circ} \mathrm{K}$ ) most of the values for $Q$ of argon at $300^{\circ} \mathrm{K}$ were between 540 and $560 \mathrm{~A}^{2}$; all of these determinations lay within a total range of $15 \%$. All the data on the temperature dependence of the cross section as reported are consistent with the "Set B" measurements for argon.

Table I summarizes the results of the study of the influence of temperature on the scattering of $\mathrm{CsCl}$ beams by various polar and nọnpolar gases. Here $T_{1}$ and $T_{2}$ represent the temperatures $\left({ }^{\circ} \mathrm{K}\right)$ of the scattering gas and beam, respectively; $\bar{T}=2 T_{1} T_{2} /\left(T_{1}+T_{2}\right)$, $v_{r}(\mathrm{~cm} / \mathrm{sec})$ is the average relative velocity as defined in I, and $Q\left(\mathrm{~cm}^{2}\right)$ is the cross section. The potential constant $C\left(\mathrm{erg} \mathrm{cm}^{6}\right)$ is obtained ${ }^{1}$ from the MasseyMohr formula,

$$
C=6.738 \times 10^{-30_{v_{r}}} Q^{5 / 2} .
$$

Listed in the table are the dipole moments $\mu$ (debyes) and polarizabilities $\alpha\left(\mathrm{A}^{3}\right)$ of the various gases [see Rothe (footnote 6 ) for sources of data].

Table II presents data on the relative cross sections for the scattering of $\mathrm{CsCl}$ beams by various nonpolar gases at $300^{\circ} \mathrm{K}$. Set A summarizes the most reliable determinations from the earlier study. ${ }^{6}$ The data of Set $B$ are derived from Table $I$. The relative cross section $Q^{*}$ is defined ( $a$ in $\mathrm{I}$ ) by the ratio

$$
Q^{*}=Q_{12} / Q_{\mathrm{Ar} 2}
$$

where $Q_{12}$ and $Q_{A r 2}$ are the total cross sections for the beam 2 with gas 1 and argon, respectively. The calculated relative cross sections are obtained from the equations [(6) and (7) of I] for the $C_{\text {ind }}$ and $C_{\text {disp }}$ terms, using the dipole moment of $\mathrm{CsCl}$ and the listed polarizabilities of the scattering gases.

The data are presented graphically in Figs. 2-12. Where different symbols for experimental points appear, they represent different series of measurements. Dashed lines through the data are "experimental," while solid lines show either the calculated fit to the data or the theoretical lines, as indicated. The dotted 
TABLE I. Temperature dependence of the cross section for the scattering of $\mathrm{CsCl}$ beams (CsCl: $\mu_{2}=10.42 ; \alpha_{2}=5.912$ ).

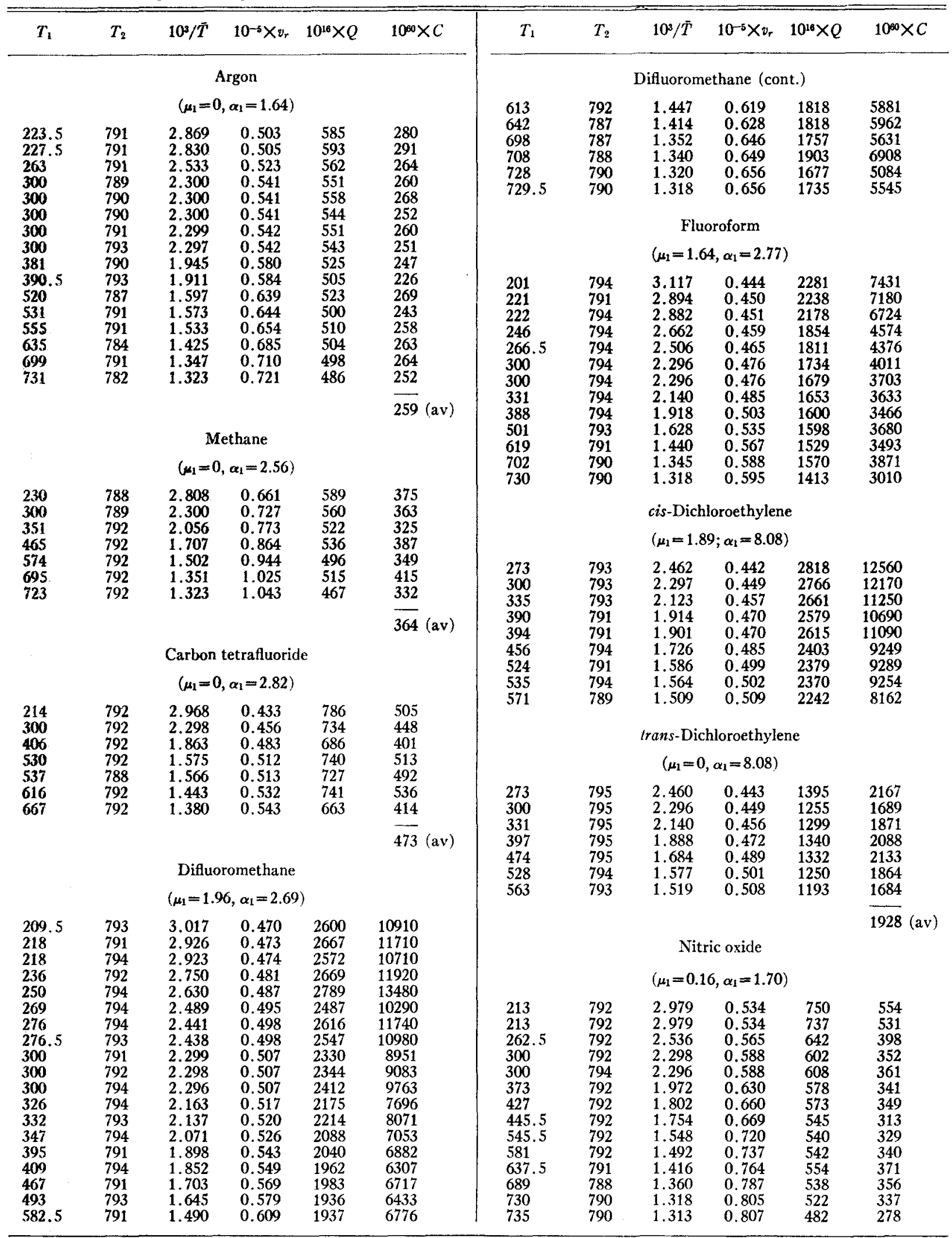


TABLE 1 Continued.

\begin{tabular}{|c|c|c|c|c|c|c|c|c|c|c|c|}
\hline$T_{1}$ & $T_{2}$ & $10^{3} / \bar{T}$ & $10^{-5} \times v_{r}$ & $10^{16} \times Q$ & $10^{30} \times C$ & $T_{1}$ & $T_{2}$ & $10^{3} / \tilde{T}$ & $10^{-5} \times v_{r}$ & $10^{16} \times Q$ & $10^{\circ} \times C$ \\
\hline \multicolumn{6}{|c|}{$\begin{array}{c}\text { Hydrogen sulfide } \\
\left(\mu_{1}=1.02, \alpha_{1}=3.61\right)\end{array}$} & \multicolumn{6}{|c|}{$\begin{aligned} & \text { Ammonia } \\
= & \left.1.47, \alpha_{1}=2.16\right)\end{aligned}$} \\
\hline $\begin{array}{l}197 \\
226 \\
260 \\
300 \\
429.5 \\
549 \\
635 \\
727\end{array}$ & $\begin{array}{l}794 \\
794 \\
794 \\
794 \\
793 \\
791 \\
790 \\
788\end{array}$ & $\begin{array}{l}3.168 \\
2.842 \\
2.553 \\
2.296 \\
1.794 \\
1.542 \\
1.420 \\
1.322\end{array}$ & $\begin{array}{l}0.508 \\
0.525 \\
0.544 \\
0.567 \\
0.633 \\
0.689 \\
0.727 \\
0.765\end{array}$ & $\begin{array}{r}1453 \\
1444 \\
1301 \\
1191 \\
1080 \\
993 \\
863 \\
793\end{array}$ & $\begin{array}{r}2750 \\
2800 \\
2241 \\
1868 \\
1635 \\
1444 \\
1070 \\
913\end{array}$ & $\begin{array}{l}204 \\
226 \\
259 \\
300 \\
300 \\
300 \\
376 \\
459 \\
552 \\
705 \\
717\end{array}$ & $\begin{array}{l}793 \\
791 \\
794 \\
790 \\
790 \\
793 \\
793 \\
794 \\
794 \\
790 \\
792\end{array}$ & $\begin{array}{l}3.082 \\
2.845 \\
2.560 \\
2.300 \\
2.300 \\
2.297 \\
1.960 \\
1.719 \\
1.536 \\
1.342 \\
1.329\end{array}$ & $\begin{array}{l}0.623 \\
0.644 \\
0.675 \\
0.712 \\
0.712 \\
0.712 \\
0.775 \\
0.839 \\
0.905 \\
1.005 \\
1.012\end{array}$ & $\begin{array}{r}1217 \\
1169 \\
1132 \\
1128 \\
1090 \\
1078 \\
1066 \\
1058 \\
1070 \\
946 \\
1078\end{array}$ & $\begin{array}{l}2168 \\
2029 \\
1960 \\
2049 \\
1879 \\
1829 \\
1936 \\
2059 \\
2287 \\
1862 \\
2603\end{array}$ \\
\hline
\end{tabular}

TABLE II. Relative cross sections for scattering of $\mathrm{CsCl}$ beams by nonpolar molecules at $300^{\circ} \mathrm{K}$.

\begin{tabular}{|c|c|c|c|c|c|c|}
\hline Scattering gas & $\alpha_{1}$ & $T_{2}$ & $10^{3} / \bar{T}$ & $10^{-5} \times v_{r}$ & $Q_{\text {obss }}^{*}$ & $Q_{\text {ealo }} *$ \\
\hline \multicolumn{7}{|c|}{ Set $\mathbf{A}$} \\
\hline $\begin{array}{l}\mathrm{Ar} \\
\mathrm{He} \\
\mathrm{Ne} \\
\mathrm{Kr} \\
\mathrm{Xe} \\
\mathrm{H}_{2} \\
\mathrm{D}_{2} \\
\mathrm{SF}_{3} \\
\mathrm{SiCl}_{4}\end{array}$ & $\begin{array}{l}1.64 \\
0.206 \\
0.408 \\
2.49 \\
4.02 \\
0.806 \\
0.796 \\
4.48 \\
11.27\end{array}$ & $\begin{array}{l}876 \\
876 \\
876 \\
876 \\
876 \\
876 \\
876 \\
876 \\
876\end{array}$ & $\begin{array}{l}2.237 \\
2.237 \\
2.237 \\
2.237 \\
2.237 \\
2.237 \\
2.237 \\
2.237 \\
2.237\end{array}$ & $\begin{array}{l}0.555 \\
1.32 \\
0.68 \\
0.475 \\
0.446 \\
1.816 \\
1.313 \\
0.441 \\
0.434\end{array}$ & $\begin{array}{l}(1.000) \\
0.37 \\
0.60 \\
1.35 \\
1.55 \\
0.52 \\
0.55 \\
1.74 \\
2.24\end{array}$ & $\begin{array}{l}(1.000) \\
0.32 \\
0.55 \\
1.24 \\
1.51 \\
0.46 \\
0.52 \\
1.68 \\
2.34\end{array}$ \\
\hline \multicolumn{7}{|c|}{ Set $B$} \\
\hline $\begin{array}{l}\mathrm{Ar} \\
\mathrm{CH}_{4} \\
\mathrm{CF}_{4} \\
\text { trans- } \mathrm{C}_{2} \mathrm{H}_{2} \mathrm{Cl}_{2}\end{array}$ & $\begin{array}{l}1.64 \\
2.56 \\
2.82 \\
8.08\end{array}$ & $\begin{array}{l}790 \\
789 \\
792 \\
795\end{array}$ & $\begin{array}{l}2.300 \\
2.300 \\
2.298 \\
2.296\end{array}$ & $\begin{array}{l}0.541 \\
0.727 \\
0.456 \\
0.449\end{array}$ & $\begin{array}{l}(1.000) \\
1.01 \\
1.33 \\
2.27\end{array}$ & $\begin{array}{l}(1.000) \\
1.04 \\
1.37 \\
2.00\end{array}$ \\
\hline
\end{tabular}

lines merely serve to connect different regions of the drawing.

\section{DISCUSSION}

\section{A. Scattering by Nonpolar Gases}

By inspection of Table I it is seen that the small observed temperature dependence of the cross section is entirely accounted for by the temperature dependence of $v_{r}$. The solid lines in Figs. 2-4 represent the calculated fit to the data ( $Q$ vs $T_{1}$ ) for $\mathrm{Ar}, \mathrm{CH}_{4}, \mathrm{CF}_{4}$ and trans $-\mathrm{CHCl}=\mathrm{CHCl}$, based on $\mathrm{Eq}$. (4) of $\mathrm{I}$,

$$
Q \sim\left(C / v_{r}\right)^{\frac{3}{5}}
$$

The temperature invariance of $C$ [calculated from $Q$ with Eq. (1)] is illustrated in Fig. 5 for Ar, Fig. 7 for $\mathrm{CH}_{4}$ and $\mathrm{CF}_{4}$, and Fig. 8 for trans- $\mathrm{CHCl}=\mathrm{CHCl}$.

It is of interest to compare these "observed" $C$ values with those calculated ${ }^{1}: C_{\text {ealc }}=C_{\text {disp }}+C_{\text {ind }}$. Table III shows this comparison; the listed values of $C_{\text {obs }}$ are the average $C$ values from Table $\mathrm{I}$.

The results are shown graphically in Figs. 5, 7, and 8 with $C_{\text {calc }}$ indicated by a horizontal (solid) line.
In terms of the reverse calculation (i.e., $Q$ from $C_{\text {calc }}$ ) for the worst case, $\mathrm{CH}_{4}, Q_{\text {cale }}$ differs from $Q_{\text {obs }}$ by some $18 \%$. Thus the agreement is fair, but there is much room for improvement. A discussion formulating possible sources for differences is presented in I.

\section{B. Scattering by Polar Gases}

The average potential for a system of two classically rotating ideal dipoles is given by the Keesom formula?

$$
\langle V(r)\rangle_{A v}=-2 \mu_{1}^{2} \mu_{2}^{2} / 3 k T r^{6}
$$

valid in the limit when

$$
\left(\mu_{1} \mu_{2} / r^{3}\right) / k T \ll 1
$$

(i.e., $T \rightarrow \infty ; \mu_{1}, \mu_{2} \rightarrow 0$; and/or $\left.r \rightarrow \infty\right) .^{8}$ For the molecular beam case it seems reasonable ${ }^{6}$ to replace $T$ by $\bar{T}=2 T_{1} T_{2} /\left(T_{1}+T_{2}\right)$, so that

$$
C_{d-d}=2 \mu_{1}^{2} \mu_{2}^{2} / 3 k \bar{T} \text {. }
$$

\footnotetext{
${ }^{7}$ W. Keesom, Physik. Z. 22, 129 (1921).
}

${ }^{8}$ As noted in I, the condition for validity of Eq. (4) is equivalent to $r \gg r_{\min }=\left(\mu_{1} \mu_{2} / k T\right)^{1 / 3}$. For $\mu_{1}=1$ debye, $\mu_{2}=10$ debyes, $T=$ $300^{\circ} \mathrm{K}, r_{\min }=6.2 \mathrm{~A}$. Thus the conditions are hardly satisfied for the present experimental situation. 


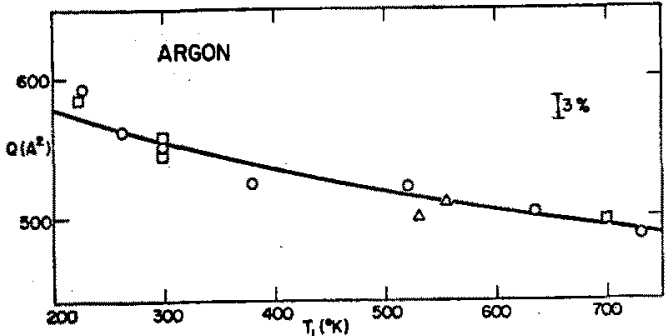

FIG. 2. $Q$ vs temperature of scattering gas: - calc fit.

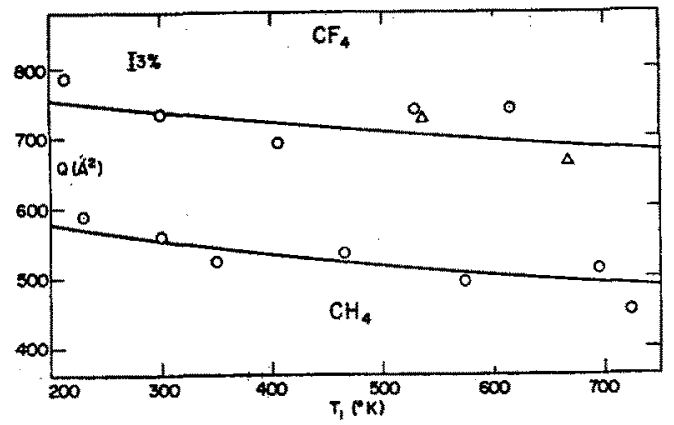

Fic. 3. $Q$ vs temperature of scattering gas: - calc fit.

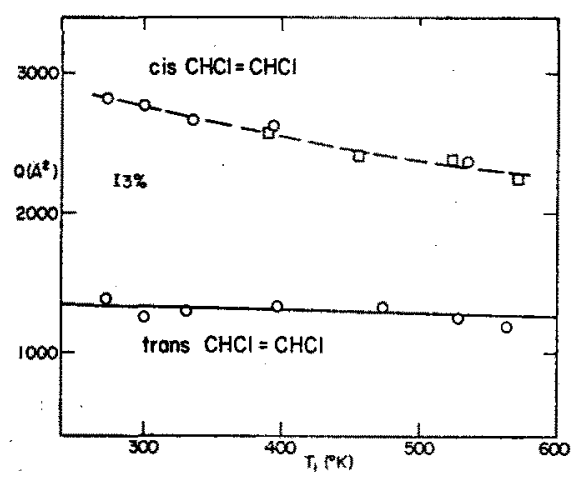

FIG. 4. $Q$ vs temperature of scattering gas: - calc fit; - - exptl.

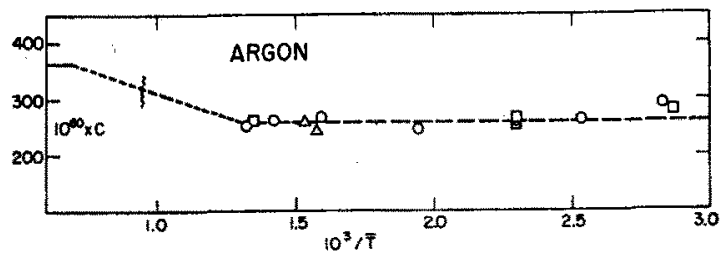

Fig. 5. C vs $1 / \bar{T}:-$ theor; - $-\operatorname{exptl}$.

TABLE III. $C_{\mathrm{calc}}$ vs $C_{\mathrm{obs}}$ for scattering by nonpolar molecules.

\begin{tabular}{lcccc}
\hline \hline Molecule & $10^{\circ 0} \times\left[C_{\text {disp }}\right.$ & $C_{\text {ind }}$ & $C_{\text {eale }}$ & $\left.C_{\text {obs }}\right]$ \\
\hline $\mathrm{Ar}$ & 186 & 178 & 364 & 259 \\
$\mathrm{CH}_{4}$ & 267 & 277 & 544 & 364 \\
$\mathrm{CF}_{4}$ & 363 & 306 & 669 & 473 \\
trans $\mathrm{CHCl}=\mathrm{CHCl}$ & 835 & 878 & 1713 & 1928 \\
\hline \hline
\end{tabular}

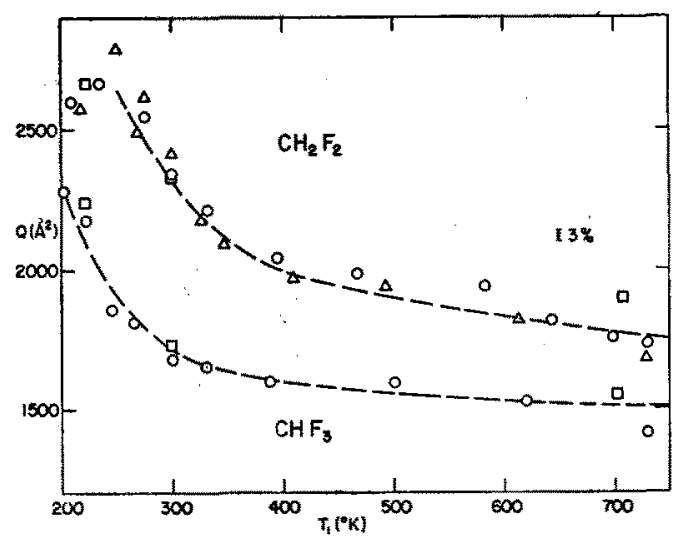

FIG. 6. $Q$ vs temperature of scattering gas: - - exptl.

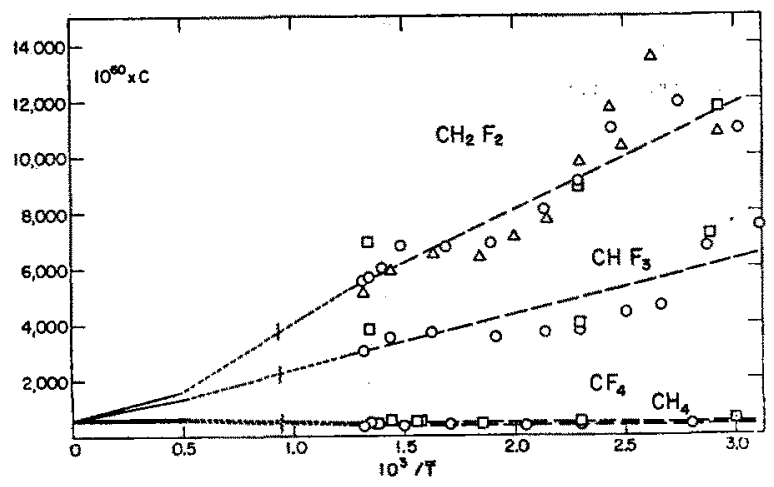

FIG. $7 . C$ vs $1 / \bar{T}:-$ theor; -- - exptl.

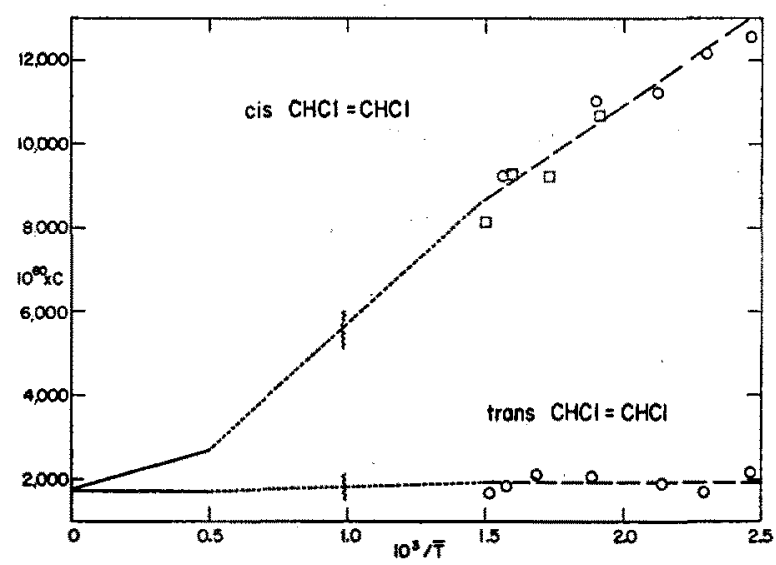

Fia. 8. C vs $1 / \bar{T}:-\cdots$ theor; - - exptl.

Thus one may write a "limiting" equation,

where

$$
C=C_{\infty}+\gamma / \bar{T}
$$

$C_{\infty}=C_{\mathrm{d} \text { isp }}+C_{\text {ind }}$ and $\gamma=d C / d(1 / \bar{T})=\frac{2}{3} \mu_{1}^{2} \mu_{2}^{2} / k$.

For $\mu_{2}=10.42$ debyes, expressing $\mu_{1}$ in debyes, $\bar{T}$ in ${ }^{\circ} \mathrm{K}$, and $C$ in erg-cm ${ }^{6}, \mathrm{Eq} .(7)$ becomes

$$
C=C_{\infty}+5.244 \times 10^{-55} \mu_{1}{ }^{2} / \tilde{T} .
$$


TABLE IV. Comparison of parameters for scattering by polar molecules.

\begin{tabular}{|c|c|c|c|c|c|c|c|c|}
\hline Molecule & $\mu_{1}$ (debyes) & $10^{60} \times$ & {$\left[C_{\mathrm{d} \text { isp }}\right.$} & $C_{\text {ind }}$ & $\left.C_{\infty}\right]$ & $10^{55} \times$ & {$\left[\gamma_{\text {cale }}\right.$} & $\left.\gamma_{\text {obs }}\right]$ \\
\hline NO & 0.16 & & 202 & 185 & 387 & & 0.13 & $(0.4)$ \\
\hline $\mathrm{H}_{2} \mathrm{~S}$ & .1 .02 & & 350 & 398 & 748 & & 5.46 & 8.6 \\
\hline $\mathrm{CHF}_{3}$ & 1.64 & & 347 & 316 & 663 & & 14.1 & 19. \\
\hline $\mathrm{CH}_{2} \mathrm{~F}_{2}$ & 1.96 & & 326 & 314 & 640 & & 20.1 & 37. \\
\hline cis $-\mathrm{C}_{2} \mathrm{H}_{2} \mathrm{Cl}_{2}$ & 1.89 & & 835 & 899 & 1734 & & 18.7 & 45. \\
\hline $\mathrm{NH}_{3}$ & $(1.47)$ & & 233 & 247 & 480 & & $(11.3)$ & $(0.0)$ \\
\hline
\end{tabular}

Table IV lists calculated values of $C_{\mathrm{d} \text { isp }}, C_{\mathrm{ind}}, C_{\infty}$, and $\gamma$. The slopes of the dashed lines drawn through the experimental points in Figs. 7, 8, 10, and 12 are listed for comparison. The solid lines near the intercepts (at $1 / \bar{T}=0$ ) are $a$ priori calculated lines based on the results given in Table IV.

For the first three (low-dipole) scattering gases, the discrepancy between the observations and the calculations is only moderate. For the next two (high-dipole) molecules, the cross sections and the "observed" $C$ values are appreciably greater than calculated. This may indicate the departure from the limiting assumptions previously discussed.

The anomalous (small) temperature dependence of the $C$ for $\mathrm{NH}_{3}$ may possibly be associated with the inversion tunneling. Additional cross-section measure-

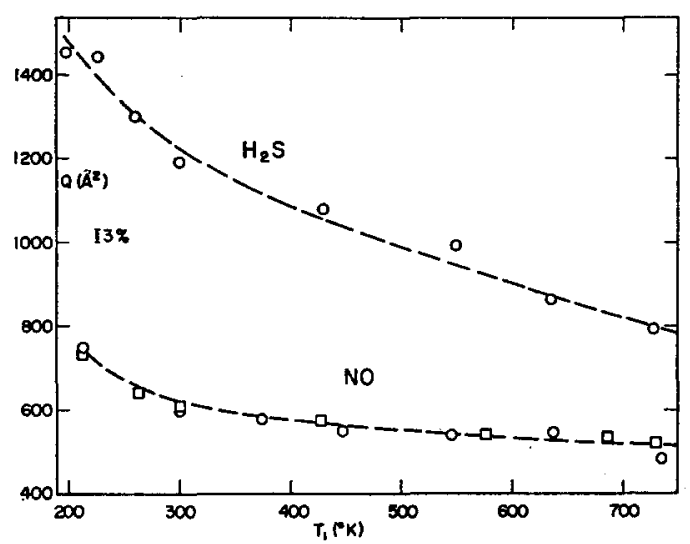

F1G. 9. $Q$ vs temperature of scattering gas: - - exptl.

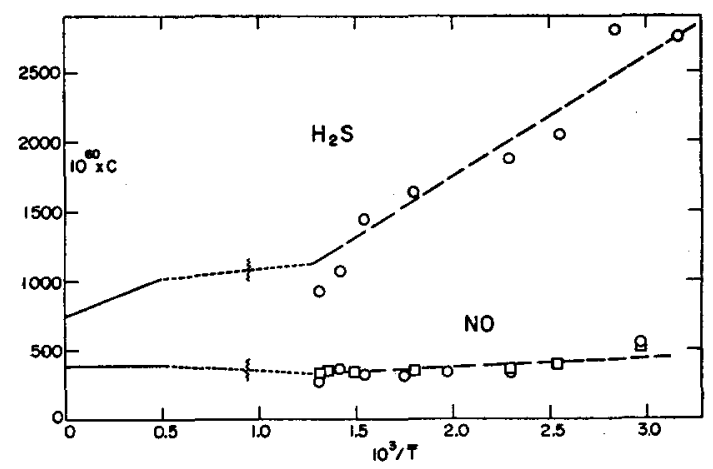

Fig. 10. $C$ vs $1 / \bar{T}:-$ theor; $--\operatorname{expt1.}$ ments with $\mathrm{ND}_{3}$ and $\mathrm{PH}_{3}$ would be desirable in order to clarify this point experimentally.

It is of interest to consider the possible origin of the difficulty with the high-dipole gases in terms of the other limiting situation (low temperature, small $r$ ) when the approaching dipoles "lock in" at close distances. Here the Keesom ${ }^{7}$ potential becomes

$$
V(r)=-C^{\prime} / r^{3}, \text { with } C^{\prime}=2 \mu_{1} \mu_{2},
$$

independent of the temperature. Thus at a given $r$ the potential is more negative. In addition, for this assumed potential the relation between $Q$ and $C^{\prime}$ is not the same as that between $Q$ and $C$ [Eq. (3)], but rather

$$
Q=1.788 \times 10^{28}\left(C^{\prime} / v_{r}\right),
$$

(upon evaluation of the Massey-Mohr equation for $s=3$ ) with the numerical constant consistent with the units employed here throughout. Sample calculations for typical cases show that the use of Eq. (11) yields calculated $Q$ 's considerably larger than obtained from Eq. (3), as expected, with a quite different temperature dependence.

A more rigorous theoretical approach is thus required in order to interpret more quantitatively the dipole-dipole scattering. The quantum mechanical

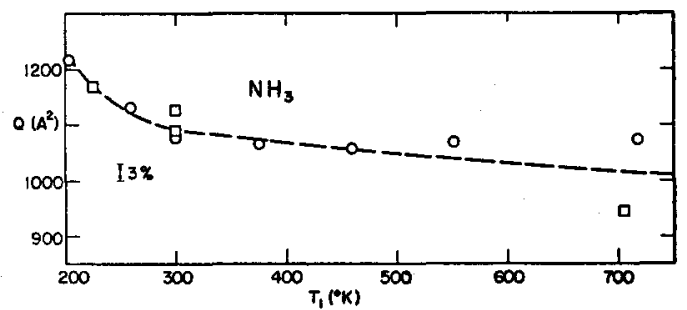

FIG. 11. $Q$ vs temperature of scattering gas: - - exptl.

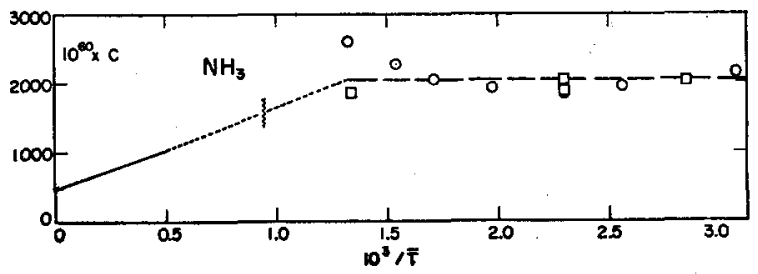

Fig. 12. $C$ vs $1 / \bar{T}:-$ theor; $--\operatorname{exptl}$. 
treatment of scattering by an angle-dependent potential (together with the problem of rotational energy transfer) is, however, a formidable one, beyond the scope of the present work.

\section{CONCLUSIONS}

(1) The cross sections for the elastic scattering of $\mathrm{CsCl}$ beams by nonpolar molecules may be predicted with fair accuracy from the Massey-Mohr formula, using the Slater-Kirkwood approximation for the dispersion term and the Debye equation for the induction force.

(2) The influence of the dipole-dipole force upon the scattering is appreciable and may be directly observed.
The scattering cross sections for the dipolar molecules are large and decrease significantly with increasing temperature.

(3) Owing to the large magnitude of the dipoledipole interaction with the $\mathrm{CsCl}$ beams, the approximate theoretical treatment accounts only semiquantitatively for the experimental observations.

\section{ACKNOWLEDGMENTS}

Thanks are due to Fred A. Morse for his assistance with some of the measurements and calculations. The authors are grateful for financial support from the Alfred P. Sloan Foundation and the U. S. Atomic Energy Commission, Division of Research.

\title{
Infrared Spectra of Alkyldiboranes. III. 1,2-Dimethyl- and 1,2-Diethyldiboranes
}

\author{
Walter J. Lehmann, ${ }^{*}$ Charles O. Wilson, Jr., $\dagger$ and I. Shapiro* \\ Research Laboratory, Olin Mathieson Chemical Corporation, Pasadena, California
}

(Received March 21, 1960)

\begin{abstract}
The infrared spectra of three isotopic variants of 1,2-dimethyldiborane-- $\left(\mathrm{CH}_{3} \mathrm{~B}^{10} \mathrm{H}_{2}\right)_{2},\left(\mathrm{CH}_{3} \mathrm{BH}_{2}\right)_{2}$, $\left(\mathrm{CH}_{3} \mathrm{BD}_{2}\right)_{2}$ - and of five 1,2-diethyldiboranes- $\left(\mathrm{C}_{2} \mathrm{H}_{5} \mathrm{~B}^{10} \mathrm{H}_{2}\right)_{2},\left(\mathrm{C}_{2} \mathrm{H}_{5} \mathrm{BH}_{2}\right)_{2},\left(\mathrm{C}_{2} \mathrm{H}_{5} \mathrm{BD}_{2}\right)_{2},\left(\mathrm{C}_{2} \mathrm{D}_{5} \mathrm{BH}_{2}\right)_{2}$, $\left(\mathrm{C}_{2} \mathrm{D}_{5} \mathrm{BD}_{2}\right)_{2}-$ are reported and frequency assignments are made. 1,2-Dialkyldiboranes are very stable with respect to decomposition, but on prolonged standing rearrange to 1,1-dialkyldiboranes. Appearance of absorptions at ca 2100 and $1550 \mathrm{~cm}^{-1}$ is the first indication of the presence of 1,1-dialkyldiborane impurity. Although not conclusive, the evidence favors existence of predominantly cis configurations.
\end{abstract}

\section{INTRODUCTION}

$\mathbf{I}^{\mathrm{N}}$ $\mathrm{N}$ the monoalkyldiboranes ${ }^{1,2}$ the vibrational character of diborane is partly preserved, in that one end of the molecule has retained both terminal hydrogens. This is not true in the 1,2-dialkyldiboranes, i.e., the sym-dialkyldiboranes, which have only a single terminal hydrogen at each end. In some respects one might expect simpler spectra for these molecules, in which both ends are alike, than for monoalkyldiboranes. However, it must be remembered that the corresponding vibrations of the two ends are not independent; they "couple," i.e., they interact with each other, producing "in-phase" and "out-of-phase" vibrations. This "splitting" may be quite considerable for some vibrations, but still, the average of the two frequencies should be relatively close to the value expected for the vibration of a single isolated unit. ${ }^{3}$ Quite often the intensity of

* Present address: Hughes Tool Company-Aircraft Division, Culver City, California.

$\dagger$ Present address: National Engineering Science Company, Pasadena, California.

${ }^{1}$ W. J. Lehmann, C. O. Wilson, Jr., and I. Shapiro, J. Chem. Phys. 32, 1088 (1960), first paper of this series.

${ }^{2}$ W. J. Lehmann, C. O. Wilson, Jr., and I. Shapiro, J. Chem. Phys. 32, (1960), second paper of this series.

${ }^{3}$ G. Herzberg, Infrared and Raman Spectra of Polyatomic Molecules (D. Van Nostrand Company, Inc., Princeton, New Jersey, 1945). one member of a pair may be so weak as to escape detection or assignment as a fundamental vibration, but if we should fail to correlate properly such a split pair of frequencies, then the apparent shifts (up or down) from the single value may become quite puzzling.

The complexity of the problem is increased because the ratio of cis to trans isomers is not known in the 1,2-dialkyl compounds. Raman spectra, if available, would probably resolve the dilemma by virtue of the difference of selection rules. For cis compounds of this sort, e.g., cis-2-butene, ${ }^{4}$ all vibrations are Raman active and all but one species $\left(A_{2}\right)$ are infrared active, yielding a large number of "coincidences." However, in trans compounds (which have a center of symmetry) infrared and Raman activities are mutually exclusive, ${ }^{3}$ allowing us to observe only one vibration of each pair.

\section{EXPERIMENTAL}

1,2-Dialkyldiborane can be prepared by direct interaction of trialkylborane with excess diborane, but the yield is so low that it is difficult to separate it from the much more abundant 1,1-dialkyldiborane. We found it more convenient to prepare 1,2-dialkyldiborane by the

${ }^{4}$ C. M. Richards and J. R. Nielsen, J. Opt. Soc. Am. 40, 442 (1950). 